\title{
Lab on a Chip: Bioreactors miniaturization for rapid optimization of biomedi- cal processes and its impact on SARS-CoV-2 diagnosis
}

C.P.Ortega ${ }^{1}$, D.A Corredor ${ }^{1}$, M.E Santillán ${ }^{1}$, W.S Ger ${ }^{1}$, C.M Noceda ${ }^{1,2}$, J.M Pais-Chanfrau ${ }^{2,3}$, L.E Trujillo ${ }^{1,2}$ DOI. 10.21931/RB/2021.06.03.31 Abstract: Lab on a Chip (LoC) as part of Microbioreactors (MBRs) constitute an emergent technology to carry out microbioprocesses based on microfluidics research. In this review, the usefulness of LoCs is exposed since its inception, demonstrating that it is a multidisciplinary research field, gathering different science branches to develop this technology. As a result, a beneficial point of advancement is reached, producing useful consumables for humanity. Some of the described LoCs throughout this work are also used to detect infectious diseases caused by bacteria or viruses, allowing accelerated studies on emerging or highimpact diseases, such as COVID-19. Here are also displayed with an updated panorama, different strategies to improve the use, applications in the biomedical field, and spread of these devices aimed at their availability to solve social problems.

Key words: Bioprocesses, COVID-19, micro bioreactors, Organ on a Chip, plasmonic, Point of Care.

\section{Introduction}

The emergence of micro-bioreactors (MBRs) comes from two main fields: microfluidic technology and molecular biology. In the early 1950s, photolithography development gave rise to microfabrication, which allowed scientists to develop the first microdevices, known as micro-size transistors. Over the years, microtechnology began to gain new approaches and applications, so chemical tests start to miniaturize. The appearance of these techniques allowed to get high precision data with a high-resolution level using small sample amounts ${ }^{1}$.

A growing interest in MBRs development, which typically works at the milliliter $(\mathrm{mL})$ and microliter $(\mu \mathrm{l})$ scale, is thought to be more convenient to collect chemical and biological information related to bioprocesses or diagnosis tests ${ }^{2,3}$. Apart from working on a micrometric scale ${ }^{4}$, the MBRs operation mode includes conventional bioreactors, discontinuous (batch), fedbatch, or continuous systems ${ }^{2}$. However, differently from conventional reactors, MRBs mainly use two modalities: those that consist of microwells and those based on microfluids ${ }^{1}$.

MBRs development was carried out to parallelize an integrative high-performance and quickly experimental design in several studies. The acceleration of quantitative microbial phenotyping stands out over conventional cultivation techniques and turns out to be economical, competitive, and effective for bioprocesses in the pharmaceutical and industrial sectors ${ }^{5}$. It seeks to miniaturize conventional cultivation to achieve MBRs that provide rapid data output, as they can be adapted by fabricating different types, sizes, and shapes. They also allow a reduction in experimentation expenses, require fewer installations and less time, and give the possibility of automation ${ }^{6}$.

Bioreactors miniaturization leads to obtaining bioprocesses or diagnosis tests just reduced to chips so-called Lab on a chip (LoC), which integrate and miniaturize some laboratory functions in a single device ${ }^{7}$. Its development is interdisciplinary since it involves biology, chemistry, physics, software sciences, and material engineering. LoCs main characteristics consist in the arrangement of multiple components integrated into a single artifact. Additionally, they can be automated; each bioprocess can be independently treated as an individual experiment in multiple microsystems ${ }^{8}$, thus increasing sensitivity, decreasing reagent consumption, and having efficient sterilization, sample detection, and product separation ${ }^{9}$.

Portable LoC platforms are used in Severe Acute Respiratory Syndrome coronavirus studies detected in 2019 (SARSCoV-2), constituting an emerging research area with significant potential for diagnosis. SARS-CoV-2 is responsible for the COVID-19 disease, which was classified as a pandemic on March 11 2020. The countries with the highest number of infections are United States, India, Brazil, Russia, and the United Kingdom, but worldwide gathered data reveals that there are a total of ninety-three million infections and more than two million confirmed deaths until January $17,2021^{10}$.

This work aims to provide an updated panorama to national researchers on the use and powerful potential applications of miniaturized systems based on Lab on a Chip, its applications in the biomedical field, and the advances that this technology offers in the study of SARS-CoV-2.

\section{MICRO BIOREACTORS}

Table 1 summarizes some of the most used MBRs models to date. The diversity of MBR designs gives the possibility to adapt the purposes of the equipment according to the user's needs and requirements. Currently, MBRs have been used in high-throughput screening techniques to evaluate the biological activity of different molecules of interest ${ }^{11}$.

Additionally, in industry, MBRs are widely used to manufacture pharmaceuticals, chemicals, enzymes, and food from cell factories ${ }^{6,12}$

An indispensable requirement in developing a bioprocess is selecting ideal conditions, such as optimal growth of microorganisms and adequate growth medium, and a strategy that guarantees the final product with the required quality. However, the productive parameters and the operational characteristics of a bioprocess can change and affect the environment's physiological and molecular cell response. Therefore, it is essential to know and study the main biochemical, microbiological, and physical factors that influence obtaining high concentrations of biotechnological products and guarantee the control of the culture and its conditions throughout the bioprocess ${ }^{13,14}$.

\footnotetext{
${ }^{1}$ Departamento de Ciencias de la Vida y la Agricultura, Laboratorio Multidisciplinario, Universidad de las Fuerzas Armadas - ESPE, Sangolquí, Ecuador.

${ }^{2}$ Grupo de Investigación de Biotecnología Industrial y Bioproductos Centro de Nanociencia y Nanotecnología - CENCINAT, Universidad de las Fuerzas Armadas ESPE, Sangolquí, Ecuador.

${ }^{3}$ FICAYA, Universidad Técnica del Norte (UTN), Ibarra, Imbabura, Ecuador.
} 
An appropriate MBR will retain the functionality of conventional bioreactors in a miniaturized form and allow the integration of additional sensors. Therefore, the following criteria should be met in an MBR: i) biocompatibility of the chosen material, ii) adequate aeration, iii) temperature control, iv) biomass measurement, v) dissolved oxygen detection, and vi) $\mathrm{pH}$ measurement ${ }^{15}$. These characteristics allow bioprocess experiments to be carried out under dynamic and flexible conditions ${ }^{1}$

\section{LAB ON A CHIP (LoCs)}

As an exciting branch of MBRs, LoCs can integrate optic (for luminescence or absorbance measurements), magnetic, electrical, and micro-resonator sensors. They allow the application of fast and effective biomarker detection protocols without being physically linked to a specialized laboratory or hospital. Thus, micro bioreactors are compacted-size devices that confer versatility to control and monitor chronic or epidemic outbreak-related diseases since they facilitate the collection, transport, extraction, and sample analysis, thus increasing the population coverage ${ }^{16}$.

The production and manufacture of LoCs follow a logical and orderly process that improves their development, which is detailed in Figure 1. The primary materials for their manufacture are silica and polymers like poly dimethyl siloxane (PDMS) and polytetrafluoroethylene (PTFE) ${ }^{7}$. Its main manufacturing methods are engraving and lithography ${ }^{17,18}$.

The transition from large laboratories to simple chips has been due to microfabrication techniques, facilitating the use of
LoCs such as Point of Care (POC) tests, which are laboratory tests that are applied near the patient's location and can be applied even by the same patient because no prior training is needed with these tests ${ }^{19}$.

LoCs has predominantly become a valuable tool for the future of medicine. For example, LoCs such as Point of Care (POC) tests constitute laboratory tests applied near the patient's location and can be applied even by the same patient since prior training is needed ${ }^{19}$. However, due to several limitations, a transition from LoCs was made to a device with a few square centimeters capable of emulating conditions of experimentation, screening, and in vitro personalized medicine of biopsies or derived cells for a multiplatform system of a tissue, which was called Organ-on-a-Chip $(\mathrm{OoC})^{20}$.

OoC systems are instruments whose main objective is to imitate the tissue-tissue interface of living organisms of the animal kingdom, focusing mainly on the most relevant processes of the organism, which include: adsorption, distribution, metabolism, and elimination ${ }^{21}$.

OoCs are microfluidic-based devices designed for the cultivation of live cells in continuously perfused micrometer-sized chambers. Generally, these micrometric chambers are composed of 3D polymeric microchannels, which are transparent and lined by living cells, which are responsible for replicating three critical aspects of intact organs: the 3D microarchitecture defined by the spatial distribution of multiple types of tissues; tissue-tissue functional interfaces; and complex organ-specific biochemical and mechanical microenvironments ${ }^{22}$.

OoC systems can be used as specialized in vitro models

\begin{tabular}{|c|c|c|c|}
\hline Model & Definition & Advantages & Usage example \\
\hline $\begin{array}{l}\text { Stirred } \\
\text { Microbio- } \\
\text { reactors }\end{array}$ & $\begin{array}{l}\text { The miniaturization } \\
\text { of stirred tanks in a } \\
\text { conventional way } \\
\text { using alternatives } \\
\text { such as } \\
\text { electromagnetic } \\
\text { stirring or magnetic } \\
\text { microbeads }{ }^{47} \text {. }\end{array}$ & $\begin{array}{l}\text { Uniform process } \\
\text { conditions, high } \\
\text { oxygen transfer rate, } \\
\text { and homogeneity. } \\
\text { Helps with } \\
\text { experimental } \\
\text { parallelization and } \\
\text { obtaining robust } \\
\text { data }^{47} \text {. }\end{array}$ & $\begin{array}{l}\text { The stirred MBR with } \\
\text { resonance achieves a } \\
\text { homogenate through } \\
\text { capillary waves; this was } \\
\text { evidenced after obtaining } \\
\text { a } 4 \text { times more } \\
\text { significant biomass } \\
\text { growth with this system } \\
\text { in the bacterium } \\
\text { Escherichia coli }{ }^{5} \text {. }\end{array}$ \\
\hline $\begin{array}{l}\text { Perfusion } \\
\text { Microbio- } \\
\text { reactors }\end{array}$ & $\begin{array}{l}\text { Membrane-based } \\
\text { systems that simulate } \\
\text { fluid flow in tissues } \\
\text { or organs }{ }^{48} \text {. }\end{array}$ & $\begin{array}{l}\text { Allow culture cells to } \\
\text { have homogeneous } \\
\text { microenvironments } \\
\text { and better mass } \\
\text { transfer conditions }{ }^{48} \text {. }\end{array}$ & $\begin{array}{l}\text { Semi-permeable } \\
\text { membrane perfusion } \\
\text { MBRs between } \\
\text { microchannels for } \\
\text { unrestricted growth and } \\
\text { bacterial screening that } \\
\text { do not limit the } \\
\text { availability of essential } \\
\text { nutrients to bacterial cells } \\
\text { and restrict chemotaxis }{ }^{49} \text {. }\end{array}$ \\
\hline $\begin{array}{l}\text { Arrays } \\
\text { Microbio- } \\
\text { reactors }\end{array}$ & $\begin{array}{l}\text { Hybrids between a } \\
\text { bioreactor and a } \\
\text { microfluidic device. } \\
\text { Represented by each } \\
\text { culture well and a } \\
\text { system that provides } \\
\text { independent media } \\
\text { flow to each well }{ }^{50} \text {. }\end{array}$ & $\begin{array}{l}\text { Smaller volume, high } \\
\text { throughput, } \\
\text { independent culture } \\
\text { wells, steady-state } \\
\text { conditions, enhanced } \\
\text { mass transport, } \\
\text { application of } \\
\text { physical signals }{ }^{50} \text {. }\end{array}$ & $\begin{array}{l}\text { Induction of } \\
\text { cardiomyocyte } \\
\text { proliferation and } \\
\text { highlight the importance } \\
\text { of in vitro screening in } \\
\text { regenerative heart } \\
\text { therapies without the use } \\
\text { of animal models in high- } \\
\text { density micro } \\
\text { bioreactors }^{51} \text {. }\end{array}$ \\
\hline
\end{tabular}

Table 1. Microbioreactor models and examples of their uses. 


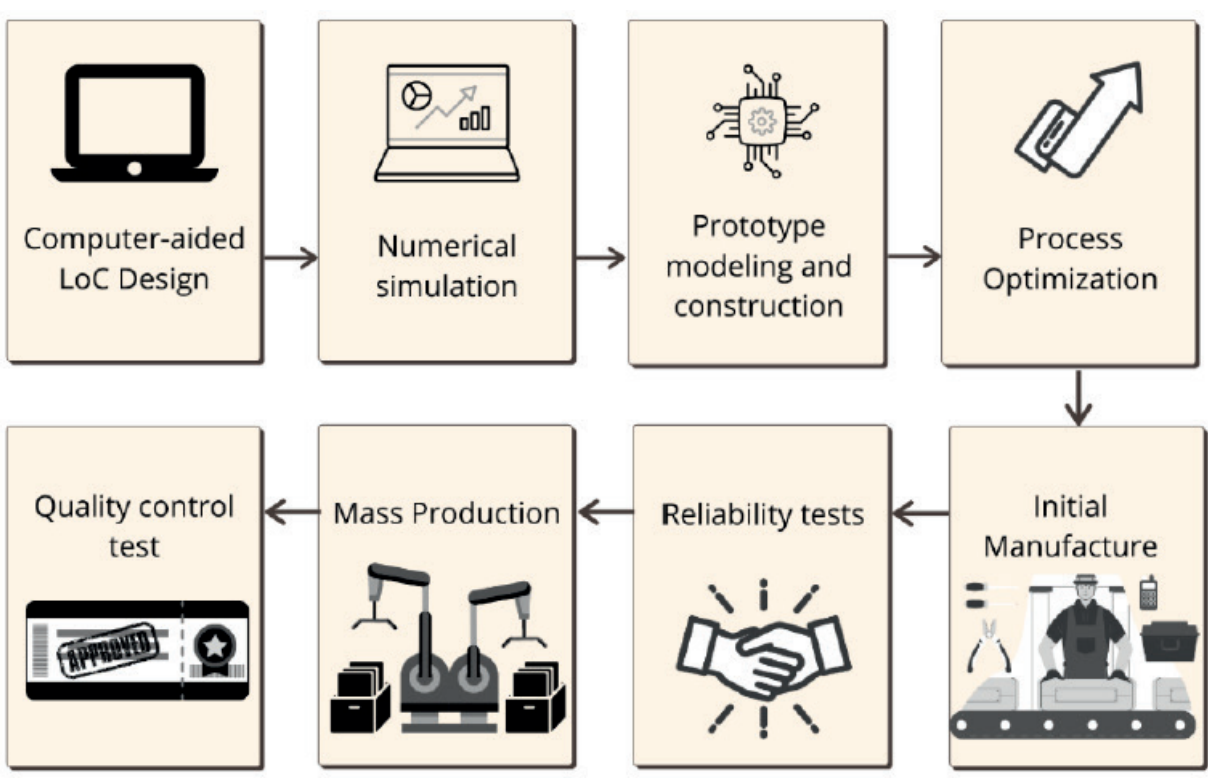

Figure 1. The process to develop a Lab on a Chip (LoC). In the case of inconveniences at any stage, the process must be repeated. Adapted from: Shanti, Teo, and Stefanini (2018) ${ }^{41}$. Created with Canva.com.

that allow the simulation of microenvironments, investigation of physical stimuli, and pharmacological modulation of complex biological processes ${ }^{22}$. Several systems can be designed, such as i) Simple systems, which have a single perfused microfluidic chamber containing a type of cultured cells that exhibit tissue functions, for example, hepatocyte systems or kidney epithelial cells. ii) Complex systems, which have two or more microchannels connected by porous membranes, lined on opposite sides by different types of cells, recreate interfaces between tissues, such as a pulmonary alveolar-capillary interface or even a blood-brain barrier ${ }^{23}$.

\section{LOCS APPLICATIONS IN BIOMEDICAL RESEARCH}

MBRs development in the health sector focuses on studying the new drugs' effects ${ }^{24}$, the development of culture systems ${ }^{25}$, production, and manufacturing of diagnostic equipment ${ }^{26}$. The main advantages in the medical sector are the cultivation of cells in three dimensions, the use of $\mathrm{OoC}$, high yield, and the production of biomass and personalized medicine applications ${ }^{27}$.

\section{Cytotoxicity studies}

OoCs are instruments that provide a variety of applications in the field of pharmacology, they stand out for their ability to imitate different environments of the animal organism to evaluate toxicity. In the study by Coppeta et al.(2017), a cross-platform design based on reconfigurable human cells that supports the function of individual organs is presented ${ }^{18}$.

Heart on a Chip $(\mathrm{HoC})$ has shown the potential to facilitate and shorten drug development. In the study by Mandenius (2018), a prototype of HoC is designed based on cardiomyocytes obtained from the development of induced pluripotent stem cells (iPSC) ${ }^{11,28}$. This and other OoC studies can be seen in Figure 2.

\section{Disease's study and diagnosis}

OoCs can simulate intracellular environments and broad screening for drugs and cell responses, whereas LoCs allow rapid diagnosis of diseases that can be detected using human fluid samples ${ }^{7,29}$. This section will provide examples of the advancement of this technology and the integration of miniaturi- zed conventional tests

LoC-based platforms have been increasingly developed for the analysis and detection of biomarkers. They allow better sample preparation, handling, high throughput, and portability. Also, provide attractive features such as marker-free detection, higher sensitivity, and the integration of novel detection techniques that reduce testing time and simplify processes ${ }^{30}$. The comparison between LoC-based platforms and conventional tests is shown in Figure 3.

Malaria is a disease that requires quick and easy ways of diagnosis, so LoCs have been beneficial for developing rapid tests $^{31}$. The main LoC diagnostic techniques to detect malaria are based on real-time capillary PCR (q-PCR), which has a sensitivity of $97.4 \%$ and a specificity of $93.8 \%$ compared to conventional q-PCR ${ }^{32}$. Other LoC-based diagnostic techniques for malaria include microfluidic chips that perform Enzyme-Linked ImmunoSorbent Assay (ELISA) to detect histidine-rich protein 2 (HRP-2). Besides, chips were developed for studies of individual cells, in which cells infected with malaria are identified for their properties in microfluidics ${ }^{31}$.

The study has extensively developed in LoC for its diagnosis and $\mathrm{OoC}$ for its culture in viruses. In a dual microchannel design with human liver cells separated by a porous membrane (liver-sinusoid-on-a-chip), an optimal replication rate of the Hepatitis B Virus (HBV) was achieved, measured by the presence of viral DNA secreted by the cells and the expression of the central antigen of hepatitis $B(\mathrm{HBcAg})$ was determined. Differentiation and functions of the hepatocytes were maintained during the trial; approximately $73.3 \%$ of the hepatocytes expressed $\mathrm{HBcAg}^{33}$.

\section{Research on SARS-COV-2}

The Severe Acute Respiratory Syndrome (SARS-CoV) caused an epidemic between 2002-2004; this misfortune allowed the development of a microfluidic system manufactured using the photolithography technique. The chip had been tested to detect the coronavirus SARS-CoV; this system had a laser fluorescence detection, capable of giving a positive rate of SARS clinical samples up to $94.44 \%$. The research had shown a higher positive rate than a conventional PCR, with shorter test times and lower costs ${ }^{34}$. 


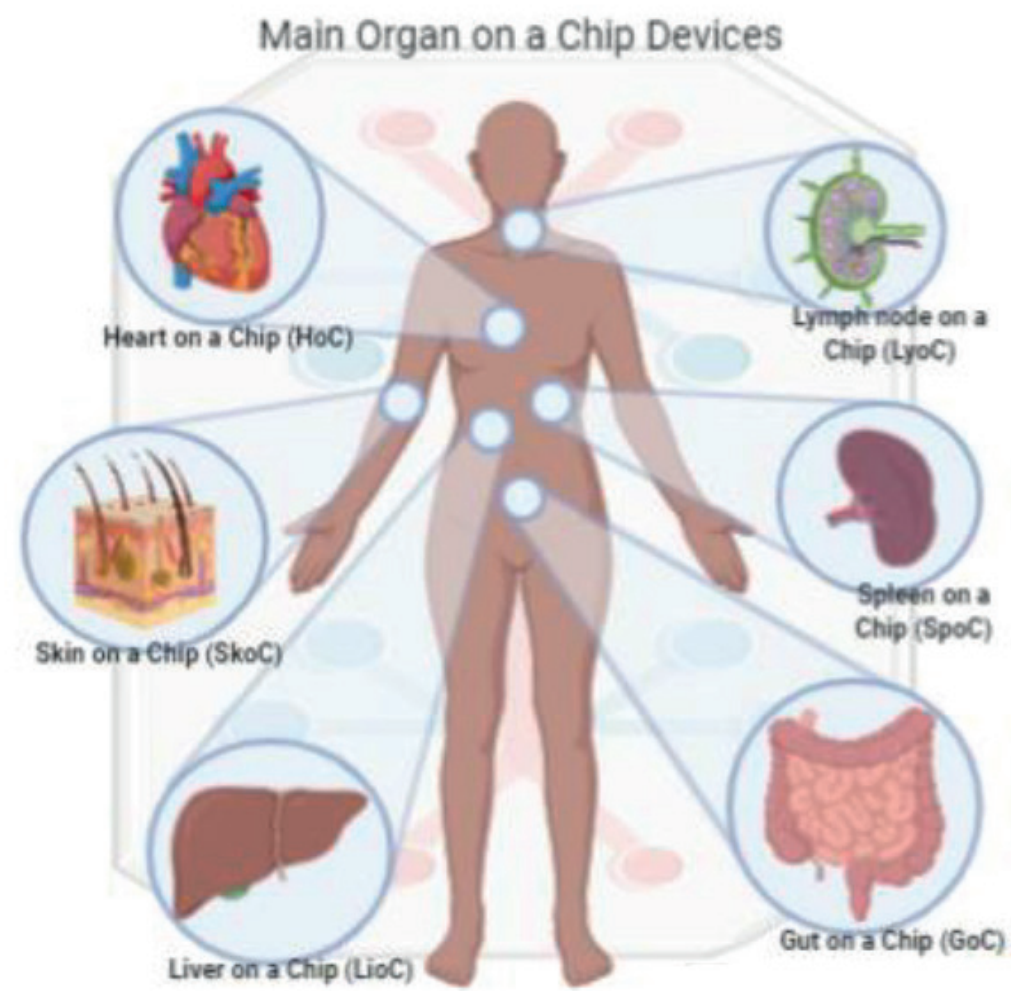

Figure 2. Main Organ on a Chip (OoC) devices, based on impermeable and microfluidic membranes to mimic the tissue-tissue interface of living organisms, Heart on a chip: a three-dimensional cell microstructure is generally used for toxicology tests in cardiomyocytes. Lymph node on a chip: used in research simulating microstructures of the paracortical region of the lymph node to examine the dynamics of interaction between dendritic cells and T cells. Skin on a chip: they are preferentially based on mimicking the active immune cells of the skin and physiological research adding vascularization in skin models with endothelial cells. Spleen on a chip: system consisting of two channels, the first one with a fast liquid flow and the other with a slow liquid flow to balance hydrodynamic forces and imitate the filter function in the spleen. Liver on a Chip: for its therapeutic research on functions, metabolism, detoxification, and response to drugs, an OoC of interest developed from hepatocytes and endothelial cells. Gut on a chip: usually used for phase I drug development and is helpful to examine the small intestine functions. Based on Shanti et al.(2018).
In the COVID-19 pandemic, LoCs were developed as diagnostic tools based on GRT-PCR; these provide significant advantages such as using a small sample volume, rapid detection, and the incorporation of the Gold Standard test to diagnose SARS-CoV-2 in a miniature portable form ${ }^{35,36}$.

Another application of LoC is to detect the RNA transduction of SARS-CoV-2 without the need for qRT-PCR. Instead, the genetic material is detected by hybridization with probes; a diode laser allows quantifying the viral RNA by excitation of the probe hybrid with the RdRp-COVID, ORFlab-COVID SARSCoV-2 and E protein genes. This technique significantly improved the stability, sensitivity, and reliability of the chip ${ }^{37}$.

A novel method for detecting SARS-CoV-2 is plasmonic, which is the excitation of a metal-dielectric target molecule that generates a signal when catching an RNA target. It has shown high sensitivity and detects samples with low concentrations of nucleic acids. These advantages allow the use of LoCs in versatile ways to detect viruses ${ }^{38}$.

SARS-CoV-2 diagnosis by qRT-PCR test didn't cover the presented demands, so some LoCs had an emergency use authorization to solve this trouble. These authorizations were given by the Food and Drug Administration (FDA) in the United States $^{39}$. The SARS-CoV-2 detection LoCs on the market can be seen in Table 2 .

Complementing the use of LoCs for diagnosis, the Applikon ${ }^{\circledR}$ company has researched the use of MBR Micro-matrix for possible vaccines against COVID-19 by the Virology Laboratory and the Bioprocess Engineering group of Wageningen University. The MBR is being applied to optimize cell growth parameters for the production of the Spike protein in Sf9 cells ${ }^{40}$.

\section{FUTURE PERSPECTIVES}

There are many possibilities for future exploration and technical issues that need to be addressed to turn MBRs emerging technologies into valuable tools. The innovation of detection methods and the miniaturization of instruments need to be improved, which requires collaboration between scientists with experience in different fields. Among the improvements that must be made, the material used to manufacture the microfluidic device must not influence the cellular response behavior. Currently, PDMS is the standard material used for manufacturing; however, it is highly lipophilic to bind to molecules in the perfusion medium or bind to introduced drugs ${ }^{41}$.

An essential requirement for commercialization and a challenge for complex microfluidic structures is scalability. As a result, scalability considerations must drive the materials, the design, and the fabrication methods used for such devices. Advances in 3D printing technology will likely start to bridge that gap shortly to build plastic-based MBRs ${ }^{42}$.

Based on the variety of diagnostic chips capable of detecting COVID-19, portability, sensitivity, and performance are the ruling guideline to implement a virus-specific diagnostic strategy. The SARS-CoV-2 biomarkers enable plasmonic and colorimetry for developing chip tests that ensure correct diagnosis, opening the possibility of an integrated POC system ${ }^{38,43}$. Given this potential for rapid results, plasmonic-based sensors can reduce the total analytical time from hours or days to minutes, which would allow patients to receive their diagnosis in less time, reducing nosocomial transmission and minimizing the burden on clinical laboratories ${ }^{38}$.

Although rapid diagnostic LoCs can bring benefits for those affected, in the future, these devices should have an integrated internet communication system with real-time data transmission capacity and updated monitoring (integrated transmitting antenna), which allows data acquisition to enter into a health network, this would have a significant impact on the management of current or future pandemics ${ }^{44}$.

A new method of detection and analysis of samples is through the use of smartphones (SP), thanks to their sophisticated technological characteristics, such as high-quality cameras, great computational power, and easy connectivity; these have facilitated its integration as an analytical detection tool. SP-based tests measure optical variables such as bright field, colorimetry, luminescence, and fluorescence ${ }^{42}$. 


\section{Lab on a Chip}

a)

b)

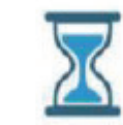

c)

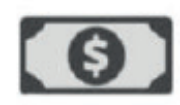

d)

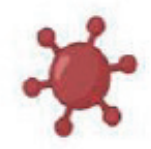

2080

e)

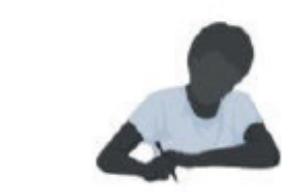

f)

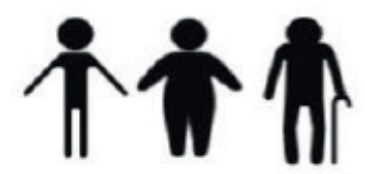

g)

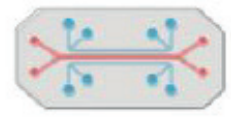

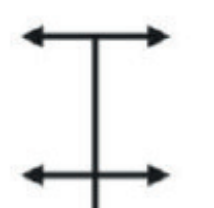

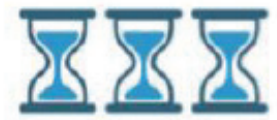
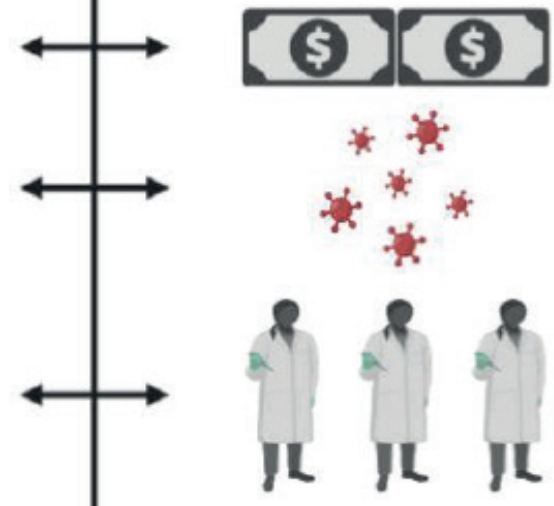

Figure 3. Comparison of Lab on a Chip (LoC) versus conventional tests. a) The time required for diagnoses in $\mathrm{LoC}$ is more minor than conventional tests. b) Your usage costs decrease due to lower reagent consumption. c) The risk of possible infections or nosocomial transmission decreases because patients obtain their results in a shorter time. d) A smaller laboratory staff is needed. e) Required training is simpler. f) The reach or coverage of the population is greater. g) Due to their portability, they facilitate handling and mobilization.
The identification of viruses using SP has been proved on different systems such as detection of Ebola virus-specific antibodies, RT-LAMP tests for detecting the human immunodeficiency virus (HIV) and Zika virus, and diagnosing influenza with gold nanoparticles test ${ }^{39}$. Sun et al.(2020) study the detection from LAMP of 5 bacterial and viral pathogens that cause respiratory infections in equines, using the SP Motorola Nexus 6 to measure fluorescence. The system managed to differentiate positive and negative controls and detect one or more pathogens simultaneously in an hour (ideal for co-infection diagnosis). Furthermore, the large capacity of SPs to be used as analytical equipment makes them an excellent option for designing rapid tests for SARS-CoV-2 without the need to invest in expensive equipment ${ }^{45}$.

Microfluidic chips provide favorable support for OoC development that capture the attention of global research due to the breakthroughs that have been made in this field. The ultimate goal of $\mathrm{OoC}$ is to integrate numerous organs on a single chip and build a more complex multi-organ chip model, ultimately achieving a "Human on a chip"46.

\section{Conclusions}

This work gave an overview of the applications of LoCs devices, highlighting their value in cytotoxicity studies and their importance as diagnostic tools, their advances in disease studies make great successes in biomedicine concerning health care. Besides, LoCs and OoCs have demonstrated the fantas- tic performance of this technology, with the most avant-garde research on LoCs focused on SARS-CoV-2, plasmonic-based chips, integration of communication systems between the tests with medical data-network and the use of SmartPhones as analytical devices. The LoCs were positioned as POC tests, which would open the door to a faster diagnosis without the need for biomedical or hospital equipment and better manage different diseases thanks to Lab on a Chips.

\section{Acknowledgements}

The authors thank the Universidad de las Fuerzas Armadas, ESPE and the Industrial Biotechnology and Bioproducts Research Group, CENCINAT, due to the opportunity provided to us as their invaluable help and guidance during the development of this work.

\section{Competing interests}

The authors declare that they have no conflicting interests.

\section{Bibliographic references}

1. Prado, R. C. \& Borges, E. R. Microbioreactors as engineering tools for bioprocess development. Brazilian J. Chem. Eng. 35, 1163$1182(2018)$

2. Pasirayi, G. et al. Microfluidic Bioreactors for Cell Culturing: A Review. 3, (2011) 


\begin{tabular}{|c|c|c|}
\hline Product & Developer & Performance \\
\hline ID NOW® & Abbott ${ }^{\mathrm{TM}}$ & $\begin{array}{l}\text { RT-PCR. Can detect } \\
\text { positive samples in } 5 \\
\text { minutes and negative } \\
\text { samples in } 13 \text { minutes. }\end{array}$ \\
\hline Filmarray ${ }^{\circledR 2.0}$ & BioFire ${ }^{\mathrm{TM}}$ & $\begin{array}{l}\text { The instrument integrates } \\
\text { nucleic acid extraction, } \\
\text { purification, PCR } \\
\text { amplification, and sequential } \\
\text { detection using microfluidic } \\
\text { technology. }\end{array}$ \\
\hline GeneXpert ${ }^{\circledR}$ & Cepheid $^{\mathrm{TM}}$ & $\begin{array}{l}\text { A small kit that integrates } \\
\text { sample preparation, nucleic } \\
\text { acid amplification, and } \\
\text { molecular detection } \\
\text { analysis. }\end{array}$ \\
\hline RTisochip ${ }^{\circledR}$ & CapitalBio $^{\mathrm{TM}}$ & $\begin{array}{l}\text { RT-PCR, not only detects } \\
\text { SARS-CoV-2 but also } \\
\text { detects } 6 \text { common } \\
\text { respiratory viruses such as } \\
\text { influenza. }\end{array}$ \\
\hline $\begin{array}{l}\text { Point of Care (POC) } \\
\text { instrument }\end{array}$ & Cannon $^{\mathrm{TM}}$ & $\begin{array}{l}\text { Amplify DNA samples and } \\
\text { detect SARS-CoV-2 in } 35 \\
\text { minutes ( } 10 \text { minutes if uses } \\
\text { respiratory samples). }\end{array}$ \\
\hline
\end{tabular}

Table 2. Products based on Lab on a Chip (LoC) are in the market for the diagnosis of SARS-CoV-2. Adapted from Zhuang et al.(2020).

3. Marques, M. P. C. \& Szita, N. Bioprocess microfluidics: applying microfluidic devices for bioprocessing. Curr. Opin. Chem. Eng. 18, 61-68 (2017).

4. Lattermann, C. \& Büchs, J. 2 Design and Operation of Microbioreactor Systems for Screening and Process Development. (2016).

5. Hemmerich, J., Noack, S., Wiechert, W. \& Oldiges, M. Microbioreactor Systems for Accelerated Bioprocess Development. Biotechnology Journal 13, (2018).

6. Nagraik, T., Salcedo, A. G., Solle, D. \& Scheper, T. Process Optimization using High Throughput Automated Micro-Bioreactors in Chinese Hamster Ovary Cell Cultivation. JoVE (Journal Vis. Exp. e60577 (2020).

7. Herold, K. E. \& Rasooly, A. Lab-on-a-Chip Technology (Vol. 1) Fabrication and Microfluidics. (2009).

8. Mohammed, M. I., Haswell, S. \& Gibson, I. Lab-on-a-chip or Chipin-a-lab: Challenges of Commercialization Lost in Translation. Procedia Technol. 20, 54-59 (2015).

9. Giannitsis, A. T. Biomeditsiiniliste kiiplaborite valmistamine. Est. J. Eng. 17, 109-139 (2011).

10. WHO. WHO Coronavirus Disease (COVID-19) Dashboard. https:// covid19.who.int/table (2020). Available at: https://covid19.who. int/table. (Accessed: December 16 2020)

11. Mandenius, C. F. Conceptual design of micro-bioreactors and organ-on-chips for studies of cell cultures. Bioengineering 5, (2018).

12. Ravindran, S. et al. Microbioreactors and Perfusion Bioreactors for Microbial and Mammalian Cell Culture. in Biotechnology and Bioengineering (IntechOpen, 2019). doi:10.5772/intechopen.83825

13. Zepeda, A. B., Pessoa Jr, A. \& Farías, J. G. Carbon metabolism influenced for promoters and temperature used in the heterologous protein production using Pichia pastoris yeast. brazilian J. Microbiol. 49, 119-127 (2018).

14. Parekh, M. et al. Microbioreactor for lower cost and faster optimisation of protein production. Analyst 145, 6148-6161 (2020).
15. Zanzotto, A. Integrated Microbioreactors for Rapid Screening and Analysis of Bioprocesses. (2005).

16. Romao, V. C. et al. Lab-on-Chip Devices: Gaining Ground Losing Size. ACS Nano 11, 10659-10664 (2017).

17. Stoytcheva, M. \& Zlatev, R. Lab-on-a-chip fabrication and application. (BoD-Books on Demand, 2016).

18. Coppeta, J. R. et al. A portable and reconfigurable multi-organ platform for drug development with onboard microfluidic flow control. Lab Chip 17, 134-144 (2017).

19. Goble, J. A. \& Rocafort, P. T. Point-of-care testing: Future of chronic disease state management? Journal of Pharmacy Practice 30, 229-237 (2017).

20.Azizipour, N., Avazpour, R., Rosenzweig, D. H., Sawan, M. \& Ajji, A Evolution of biochip technology: A review from lab-on-a-chip to organ-on-a-chip. Micromachines 11, 1-15 (2020).

21. Khalid, N., Kobayashi, I. \& Nakajima, M. Recent lab-on-chip developments for novel drug discovery. Wiley Interdiscip. Rev. Syst. Biol. Med. 9, 1-17 (2017).

22. Esch, E. W., Bahinski, A. \& Huh, D. Organs-on-chips at the frontiers of drug discovery. Nature Reviews Drug Discovery 14, 248 260 (2015).

23. Bhatia, S. N. \& Ingber, D. E. Microfluidic organs-on-chips. Nature Biotechnology 32, 760-772 (2014).

24. Christoffersson, J. \& Mandenius, C. F. Using a microfluidic device for culture and drug toxicity testing of 3D cells. in Methods in Molecular Biology 1994, 235-241 (Humana Press Inc., 2019).

25. Velugula-Yellela, S. R. et al. Use of high-throughput automated microbioreactor system for production of model igGl in $\mathrm{CHO}$ cells. J. Vis. Exp. 2018, 58231 (2018).

26. Barisam, M., Saidi, M. S., Kashaninejad, N. \& Nguyen, N. T. Prediction of necrotic core and hypoxic zone of multicellular spheroids in a microbioreactor with a U-shaped barrier. Micromachines 9, (2018). 
27. Gottwald, E. \& Altmann, B. Advanced 3D-Cell Culture Techniques in Micro-Bioreactors. (2020).

28. Marsano, A. et al. Beating heart on a chip: A novel microfluidic platform to generate functional 3D cardiac microtissues. Lab Chip 16, 599-610 (2016).

29. Hemmerich, J. et al. Less Sacrifice, More Insight: Repeated Low-Volume Sampling of Microbioreactor Cultivations Enables Accelerated Deep Phenotyping of Microbial Strain Libraries. Biotechnol. J. 14, 1-26 (2019).

30.Wu, J. et al. Lab-on-a-chip platforms for detection of cardiovascular disease and cancer biomarkers. Sensors (Switzerland) 17, (2017).

31. Kolluri, N., Klapperich, C. M. \& Cabodi, M. Towards lab-on-a-chip diagnostics for malaria elimination. Lab Chip 18, 75-94 (2018).

32. Taylor, S. C. \& Mrkusich, E. M. The state of RT-quantitative PCR firsthand observations of implementation of minimum information for the publication of quantitative real-time PCR experiments (MIQE). J. Mol. Microbiol. Biotechnol. 24, 46-52 (2014).

33. Kang, Y. B., Rawat, S., Duchemin, N., Bouchard, M. \& Noh, M. Human liver sinusoid on a chip for hepatitis B virus replication study. Micromachines 8, 1-13 (2017).

34.Zhou, X. et al. Determination of SARS-coronavirus by a microfluidic chip system. Electrophoresis 25, 3032-3039 (2004).

35. Sharma, S., Kumar, V., Chawla, A. \& Logani, A. Rapid detection of SARS-CoV-2 in saliva: can an endodontist take the lead in pointof-care COVID-19 testing? International Endodontic Journal 53, 1017-1019 (2020).

36. Udugama, B. et al. Diagnosing COVID-19: The Disease and Tools for Detection. ACS Nano 14, 3822-38Udugama, B., Kadhiresan, P., Kozlowski, H. (2020).

37. Qiu, G. et al. Dual-Functional Plasmonic Photothermal Biosensors for Highly Accurate Severe Acute Respiratory Syndrome Coronavirus 2 Detection. ACS Nano 14, 5268-5277 (2020).

38. Tymm, C., Zhou, J., Tadimety, A., Burklund, A. \& Zhang, J. X. J. Scalable COVID-19 Detection Enabled by Lab-on-Chip Biosensors. Cell. Mol. Bioeng. 13, 313-329 (2020).

39.Zhuang, J., Yin, J., Lv, S., Wang, B. \& Mu, Y. Advanced "lab-on-achip" to detect viruses - Current challenges and future perspectives. Biosensors and Bioelectronics 163, (2020).
40.Applikon. Applikon bioreactors used in search for COVID-19 vaccine. (2020). Available at: https://www.applikon-biotechnology.com/en/about-applikon/news-events/applikon-bioreactorsused-in-search-for-covid-19-vaccine/. (Accessed: December 16 2020)

41. Shanti, A., Teo, J. \& Stefanini, C. In vitro immune organs-on-chip for drug development: A review. Pharmaceutics 10, (2018),

42. Arshavsky-Graham, S. \& Segal, E. Lab-on-a-Chip Devices for Pointof-Care Medical Diagnostics. in (2020). doi:10.1007/10_2020_127

43.Zhu, H., Fohlerová, Z., Pekárek, J., Basova, E. \& Neužil, P. Recent advances in lab-on-a-chip technologies for viral diagnosis. Biosens. Bioelectron. 153, 112041 (2020).

44.Zhu, H., Fohlerová, Z., Pekárek, J., Basova, E. \& Neužil, P. Recent advances in lab-on-a-chip technologies for viral diagnosis. Biosens. Bioelectron. 153, 112041 (2020).

45.Sun, F. et al. Smartphone-based multiplex 30-minute nucleic acid test of live virus from nasal swab extract. Lab Chip 20, 1621-1627 (2020)

46.Wu, Q. et al. Organ-on-a-chip: Recent breakthroughs and future prospects. BioMedical Engineering Online 19, (2020).

47. Tan, C. K. et al. Electromagnetic stirring in a microbioreactor with non-conventional chamber morphology and implementation of multiplexed mixing. J. Chem. Technol. Biotechnol. 90, 1927-1936 (2015)

48. Jonczyk, R. et al. Living Cell Microarrays: An Overview of Concepts. Microarrays 5, 11 (2016).

49.Vit, F. F. et al. Perfusion microbioreactor system with permeable membranes to monitor bacterial growth. J. Chem. Technol. Biotechnol. 94, 712-720 (2019).

50.Figallo, E. et al. Micro-bioreactor array for controlling cellular microenvironments. Lab Chip 7, 710-719 (2007).

51. Titmarsh, D. M. et al. Induction of human iPSC-derived cardiomyocyte proliferation revealed by combinatorial screening in high density microbioreactor arrays. Sci. Rep. 6, 1-15 (2016).

Received: 2 March 2021

Accepted: 12 July 2021 